\title{
La intriga policial como trompe l'oeil en las novelas de Pablo de Santis
}

\author{
MARÍA CRISTinA G UIÑAZUं*
}

Resumen:

Este artículo tiene como propósito mostrar los cambios que ha sufrido la novela policial a lo largo del siglo XX; es especialmente en tres novelas de Pablo de Santis: Filosofía y L etras (1998), L a traducción (1998) y E 1 teatro de la memoria (1999). Se tratan aspectos importantes como el uso de las consabidas convenciones estructurantes del relato. El crimen, su investigación y la solución definitiva del enigma muestran originalidad por las renovaciones genéricas que las ubican dentro de la epistemología del fin de siglo. Se observa que los espacios del crimen tienen ahora un lugar en aquellos destinados a la conservación y diseminación de la cultura. Se analiza el contexto político de la Argentina de la posdictadura y se parodia la figura del detective. Se demuestra que la renovación que aportan las novelas de D e Santis al género policial se debe a la compleja relación crítica que entablan con el contexto en que han sido producidas y con el lenguaje y los códigos del género. Dichas novelas no pretenden llevar a cabo un análisis político o social según las pautas del realismo, sino que el tema fundamental consiste en observar el proceso literario, así como los cuestionamientos que invitan a la reflexión y a la polémica.

Palabras clave:

Literatura argentina contemporánea, novela policial, novela posdictatorial, narrativa argentina de fin de siglo, Pablo de Santis.

${ }^{*}$ City University of New York. 
El género policial ha sufrido numerosos cambios en la literatura argentina a lo largo del siglo XX. De los relatos lúcidamente inventivos de Borges y Bioy Casares de los años cuarenta se pasa a las novelas de los años setenta y ochenta. Bajo la influencia de Raymond Chandler y de Dashiell Hammet integran problemáticas mayormente sociales y políticas. Ricardo Piglia, Osvaldo Soriano y Mempo Giardinelli, siguiendo estéticas disímiles, han elaborado narraciones contestatarias a las políticas dictatoriales de esos años. A finales de siglo, la estructura de la novela policial se renueva en la trama de tres novelas de Pablo De Santis: Filosofía y L etras (1998), L a traducción (1998) y El teatro de la memoria (1999). En estas novelas, el uso de los consabidas convenciones estructurantes del relato: el crimen, su investigación y la solución del enigma recobran originalidad por el distanciamiento que las separa de la preceptiva que codifica el género en sus dos vertientes: novela de misterio y novela negra.

\section{Los espacios del crimen}

Las novelas bajo estudio no se desarrollan en ambientes de lujo como suele acontecer en la novela de misterio, ni tampoco en las calles peligrosas de los bajos fondos urbanos de la novela negra. Contrariamente a las fórmulas acostumbradas, las tramas tienen lugar en espacios destinados al estudio, conservación y diseminación de la cultura. Se trata de espacios fuertemente cargados de significado puesto que en ellos se cataloga y organiza el saber. Filosofía y L etras tiene lugar en el instituto de literatura nacional de esa facultad; L a traducción en un hotel sede de un congreso de traductores y $\mathrm{E} l$ teatro de la memoria en una fundación dedicada a la investigación de dicha facultad.

El privilegio y la autoridad que estas instituciones confieren a sus directores y a quienes allí desarrollan sus actividades, contrastan con el estado de negligencia en que se encuentran. Mientras que la biblioteca, casi abandonada, aloja escombros y pilas de li- 
bros y documentos en diferente estado de deterioro, la construcción del hotel ha quedado interrumpida y toda un ala del edificio permanece inhabitable. La fundación, por su parte, se ubica en una construcción destinada a otros usos: "El edificio había sido en sus orígenes una fábrica metalúrgica que quedó abandonada cuando la ley obligó a erradicar de la ciudad a todas las industrias [... ] Había sectores a medio construir, galpones en los que se acumulaban maquinarias de los antiguos dueños, toneladas de chatarra" (16).

La ironía entre la supuesta importancia de la institución y su estado calamitoso es indicio de la pérdida de influencia de las organizaciones culturales en la política y en la vida pública de fin de siglo. Los escenarios entre cómicos y patéticos revelan la desvalorización de las labores relacionadas con el saber científico y artístico. La trama policial da curso a preocupaciones que van más allá de la resolución del crimen: al llamar la atención sobre la falta de interés ante la pérdida del patrimonio cultural alude a problemas sociales y económicos relacionados con la larga crisis política, económica y social de Argentina. Así comentan la situación el bibliotecario del instituto nacional y el sereno del edificio:

-Todos los libros van a terminar así. No es mi problema. Escombros y humedad y libros deshechos: es todo lo que hay aquí. Vuelva a su lugar. No se preocupe por nada. ¿Oye ese ruido?

-No oí nada.

-Son los insectos que comen la madera, los pisos, las vigas. Oiga el ruido del agua al filtrar las paredes. Un techo se acaba de desplomar. (20)

En esos edificios en vías de destrucción desempeñan sus actividades personajes que, ocupados en investigaciones obsesivas, se sienten instados a cumplir desde las más nimias e inútiles tareas hasta los crímenes más abyectos. Además, y como se verá más adelante, en tanto símbolos de la codificación de la tradición nacional, la biblioteca y el archivo figuran como espacios caducos y vacíos de sentido. 
E 1 teatro de la memoria, novela de tono más sombrío que las otras dos que aquí se estudian, da prioridad al sentido de alienación de los personajes respecto al medio y a los demás. Allí, uno de ellos comenta el proyecto de una ciudad realizado por un arquitecto desaparecido:

Nada decía de los habitantes de la ciudad; nada tampoco de frentes decorados o de muebles; solamente algunos emblemas distribuidos aquí y allá, que no encerraban ningún significado: símbolos vacíos que evocaban el vacío, símbolos abstractos que declaraban la abstracción. Pensé en las plazas de De Chirico y en los grabados de Piranesi; pero esta ciudad era todavía más secreta e inhumana. (53)

Si en tanto construcción social toda ciudad constituye un repositorio de memorias y formula un modo de comunicación, esas funciones quedan aquí canceladas porque no hay posibilidad de vestigios humanos. La imagen miniaturizada y abstracta de esta ciudad desafía cualquier intento de estudiarla y comprenderla y, como los anaqueles inútiles de la biblioteca, es espacio sin dimensión histórica y por tanto, sin significado. La vacuidad que la caracteriza le otorga una dimensión "secreta e inhumana" y la vuelve emblema del silencio y de la soledad. De igual manera que Filosofía y L etras, en esta novela adquiere relevancia el contexto político de Argentina bajo la dictatura de finales de la década del setenta. Durante esos años, la ciudad aterrorizada sin libertad de expresión y bajo la vigilancia de una censura silenciadora se tornó lugar de historias secretas.

Lo observado hasta ahora permite afirmar que el espacio en las tres novelas tiene una función desestabilizadora que provoca sugerencias y cuestionamientos de alcance extratextual.

En un nivel literario los espacios evocados en las novelas producen el mismo efecto claustrofóbico que los ambientes cerrados de la novela policial clásica. Tanto la biblioteca con sus pilas desordenadas de libros como la fundación centrada en el teatro de la 
memoria y el hotel, con sus playas aledañas, obligan a recorridos laberínticos y rutinarios. Sin embargo, y en esto radica una de las diferencias con las novelas de enigma, los protagonistas no tienen dominio sobre el espacio que recorren. Sus trayectos obedecen a los planes que otros, los criminales, han ideado para ellos. En esos ambientes, las hipótesis intelectuales propuestas demuestran ineficacia y a veces hasta peligrosidad, ya que pueden llevar a cometer otros crímenes.

\section{El contexto político}

La trama policial en las novelas de De Santis sirve de vehículo a preocupaciones muy variadas que las relacionan con el contexto en el que se producen. En Argentina, durante la década de los ochenta alternaron dos discursos disímiles referidos al terror de estado impuesto por las dictaduras militares de la década precedente: por un lado, surgieron artículos periodísticos de denuncia y el informe de título elocuente, N unca más y, por otro, el discurso de la política dominante culminó en la ley del punto final y en el indulto de los miembros de las fuerzas armadas. El primer discurso investigó y recopiló datos para establecer una memoria de las persecusiones, torturas y desapariciones; el segundo, intentó imponer la amnesia colectiva bajo pretexto de la pacificación. De las tres novelas aquí tratadas, E 1 teatro de la memoria alude con mayor insistencia a la situación política de la Argentina de la posdictadura.

Los personajes, un científico y un arquitecto cooperan en la creación de un instituto dedicado a las manipulaciones del funcionamiento de la memoria; los pacientes sufren, como sucedió con el pueblo argentino, sucesivos golpes de shock que alteran su posibilidad de rehacer la historia tanto individual como colectiva. En la fundación del Dr. Fabrizio borran las memorias propias e insertan otras, ajenas, poniendo en funcionamiento una máquina que permite el viaje por la memoria de otro. La tematización de la memoria está acentuada por las alusiones a los hechos más terribles de la 
política argentina de las últimas décadas: los desaparecidos, el uso de la tortura como método de interrogación y la guerra de Malvinas. Aníbal Diagó se anuncia como desaparecido -en el desarrollo de la novela se sabe que fue víctima de un asesinato- mientras que Fabrizio estudia documentos obtenidos bajo tortura con el objeto de determinar como se "arma, con restos de historias verdaderas, una historia falsa" (71).

Por otra parte, otro personaje busca a su hijo, marino muerto en la guerra, cuyo destino se niega a aceptar. Aunque estos episodios no constituyen focos centrales en el relato ni se hallan acompañados de propuestas ideológicas, son reconocidos por el lector como constitutivos de la historia reciente y, por consiguiente, refuerzan la memoria colectiva.

La mención de esos momentos históricos trágicos crea en la narración nódulos de resistencia frente a la tendencia a querer olvidar el pasado. Como lo demostraron Bergson y Halbwachs, la memoria tiene un papel preponderante en la constitución de la identidad individual y social. Su alteración y desaparición deforma y hasta aniquila la idea que el individuo tiene de sí mismo, de su relación con los demás y de su percepción del mundo. Es por eso que las situaciones presentadas en el relato refuerzan el sentido de disociación comentado anteriormente y que los personajes experiementan con obvias consecuencias aniquiladoras de partes de la identidad nacional y de la conciencia histórica.

E 1 teatro de la memoria es la novela que mejor ejemplifica la disociación identitaria de los personajes al mostrar la quiebra entre el ser y el nombre. El doctor Nigro es llamado D r. Nadie mientras que la identidad de otros personajes desaparece bajo etiquetas desfiguradoras: así el NN que marca los objetos de pacientes sin nombre propio y sin memoria. Como los libros en blanco de Filosofía y L etras, la identidad de los personajes - o su falta de identidadseñala en $\mathrm{E} 1$ teatro de la memoria la carencia de correspondencia en el lenguaje entre significado y significante.

La arbitrariedad lingüística se traslada igualmente a la investigación detectivesca que se torna confusa ya que la identidad y los 
signos que la representan dejan de ser confiables. Así también criminal, intelectual e investigador llegan a confundirse al igual que los valores relacionados con categorías morales. En este sentido, podemos afirmar que De Santis coincide con los comentarios que Michel Foucault hiciera sobre el intelectual ya en 1972: "The intellectual's role is no longer to place himself 'somewhat ahead and to the side' in order to express the stifled truth of the collectivity; rather, it is to struggle against the forms of power that transform him into its object and instrument in the sphere of 'knowledge,' 'truth, 'consciousness,' and 'discourse' " (207-08). El historiador francés previó el peligro de convertirse en agente del poder. Los estudiosos e investigadores que pueblan estas novelas, concentrados en estudios ineficaces, se vuelven en algunos casos colaboradores del régimen. La narrativa de De Santis desafía a los "letrados" a independizarse del discurso oficialista.

\section{La parodia}

Las novelas aquí tratadas se distancian de las pretensiones del género policial por restablecer el orden en el mundo con la solución del crimen; en ellas, lograr una comprensión concluyente es tan ilusorio como concebir una metodología razonadora y eficaz. Ricardo Piglia dice sobre la característica fundamental del policial clásico: "Se valora antes que nada la omnipotencia del pensamiento y la lógica imbatible de los personajes encargados de proteger la vida burguesa" (68). De manera contraria, las novelas estudiadas minan la fe en el poder organizador de la lógica. Para notar cómo lo logran es necesario reobservar algunos de sus aspectos.

La novela que estudia con mayor minucia esa imposibilidad es L a traducción. Allí los asesinatos en serie que ocurren en el congreso de traductores tienen por víctimas a los estudiosos de las lenguas míticas, tal como el lenguaje enoquiano, lenguaje hermético, prebabélico, de valor único y por ello, lenguaje de la muerte, "la lengua del Aqueronte es una invitación a cruzar el río" (163). La 
quimera de la lengua prebabélica condena a la búsqueda de la posibilidad de alguna traducción, a cualquier código.

En Filosofía y Letras los procesos cognoscitivos son igualmente parodiados por una acumulación de recursos. Allí tres críticos literarios compiten en el estudio de la obra de un tal Homero Brocca, obra imposible de hallar. El único cuento que subsiste, titulado significativamente "Sustituciones", se duplica en numerosas versiones imposibilitando determinar cuál es la definitiva. Si la validez del conocimiento en la modernidad se basaba en el significado y en la veracidad de los textos, en Filosofía y L etras queda reducida a vagos recuerdos fundamentados en invenciones parciales de textos inexistentes. La ridiculización del cuento de Brocca deriva de su autenticidad improbable y de la dificultad de adjudicarle una historia que lo una a la tradición. ${ }^{1}$

El vaciamiento de la autoridad del texto trae consigo la inutilización del trabajo del intelectual. Todos los textos mencionados en la novela enfatizan cómica e hiperbólicamente este hecho: libros y tesis polvorientos se acumulan desordenadamente; cuando algunos libros parecen corresponder a los buscados sólo contienen páginas en blanco o, peor aún, la misma oración repetida desde el principio al final: "este cuaderno está vacio". ${ }^{2}$

Del mismo modo en El teatro de la memoria el proyecto de representar en el espacio las épocas históricas de una manera totalizante, tal como lo había hecho Giulio Camillo en el Renacimiento, está destinado al fracaso. Para Camillo el pensamiento mítico y alegóri-

${ }^{1}$ Como señalara Benjamin: "The authenticity of a thing is the essence of all that is transmissible from its beginning, ranging from its substantive duration to its testimony to the history which it has experienced. Since the historical testimony rests on the authenticity, the former, too, is jeopardized by reproduction when substantive duration ceases to matter. And what is really jeopardized when the historical testimony is affected is the authority of the object" (Walter Benjamin, The Work of A rt in the A ge of Mechanical Reproduction, II).

${ }^{2}$ Esta caricaturización recuerda el tono de ironía burlesca con que los literatos fueran descritos en "El dios de los toros" por Borges y Bioy Casares en Seis problemas para don Isidro Parodi. 
co favorecía la creencia en una correspondencia interna entre las partes del universo; esa idea, a finales del siglo XX se reduce a la memoria de un plan inalcanzable. ${ }^{3}$

\section{La figura del detective}

Los personajes encargados de la pesquisa policial añaden relieve a la perspectiva irónica de las novelas ya que no corresponden a los modelos reconocidos: no son razonadores infalibles al modo de D upin o de Sherlock Holmes, ni detectives vulnerables aunque centrales a la manera de Marlowe. Se trata de intelectuales en mayor o menor grado frustrados que por circunstancias ajenas a su voluntad se convierten en investigadores e intervienen en la trama desde una posición marginal. En la novela policial, tanto en la de misterio como en la negra, el detective tiene el papel del héroe, en las que aquí se estudian no ocurre lo mismo. Ha comentado Giardinelli: "El protagonista de estas novelas policiales negras en Latinoamérica no logra imponer su acción como un logro personal, no es un héroe como lo son los detectives de las novelas norteamericanas. Es aplastado por la propia situación. No puede contra ella". A simismo Carlos $\mathrm{G}$ amerro, haciendo referencia al contexto histórico social de fin de siglo, comenta que debido a la institucionalización del crimen la figura de un detective honesto en la novela argentina de los años noventa resultaría exótico y obsoleto (6). ${ }^{4}$

3 "Camillo was writing at a time when encyclopaedias were being created and it was thought that it was possible to collate every known fact about the world, and that everything was cosmically connected. So inside his astronomical world system we not only get theories about planetary arrangement but also about how the planets affect our health and every other aspect of our lives". Kate Robinson, "Giulio Camillo's L'idea del Teatro". http:/ / www.sharp.arts.gla.ac.uk/ e-sharp Kate_Robinson-Giuilo_Camillo.htm.

${ }^{4}$ E ste crítico explica que en la tradición literaria argentina, el héroe no es el juez de Paz sino sus víctimas: "Nuestros héroes son el gaucho renegado Martín Fierro, Juan Moreira, Hormiga Negra, Bairoletto, Facón G rande - paradigmáticamente - el sar- 
En las novelas de De Santis, el intelectual cumple la función de detective pero tiene un rol protagónico marginal; movido más por la curiosidad que por el deber - se asemeja en esto al detective de la novela de misterio- lleva a cabo búsquedas que le interesan parcialmente ya que otras actividades profesionales retienen su atención.

El desempeño del investigador, sin embargo, se consagra indefectiblemente en la función que ejerce al final de sus pesquisas, es decir como narrador del relato que leemos. Pero si el investigador narra el relato, le toca al criminal inventar la historia. Como en "La muerte y la brújula" es él quien impone su voluntad y maneja la acción de los demás. En F ilosofía y L etras, el narrador sobrevive porque así lo desea el criminal; en El teatro de la memoria, el Dr. Nigro queda atrapado en la voluntad de Fabrizio; en L a traducción, Miguel De Blast no consigue evitar la última muerte. ${ }^{5}$

La renovación que aportan las novelas de De Santis al género policial se debe sobre todo a la compleja relación crítica que entablan con el contexto en que han sido producidas y sobre todo con el lenguaje y los códigos del género policial. Aunque establecen conexiones con la situación social y política argentinas, como aquí se ha notado, las problemáticas desarrolladas sobrepasan esa finalidad. De Santis comenta sobre Filosofía y L etras: "es un policial pero hay muchos otros elementos. Las motivaciones, las pistas, hasta el arma, todo pertenece al ámbito intelectual o, mejor, al literario" (Vázquez). Aunque las tramas se hallan firmemente ancladas en el fin de siglo, en Argentina, no pretenden llevar a cabo un estudio político o social, según las pautas del realismo. En este aspecto se separan de las novelas negras norteamericanas. ${ }^{6}$ El tema fundamen-

gento Crus, que se pasa de bando y luchajunto al desertador y contra sus propios hombres".

${ }^{5}$ Como en las novelas de Patricia Highsmith, las circunstancias determinan quiénes llevan a cabo la investigación y quiénes actúan como criminales siendo a veces, la distinción entre ambos, conflictiva. El Dr. Niro que busca comprender cómo y por qué tienen lugar los asesinatos en $\mathrm{E} I$ teatro dela memoria acaba por matar él mismo a un personaje. 
tal, como lo afirma el autor, consiste en estudiar el proceso literario. La figura del lector corresponde aquí como en buena parte del género policial, a la del detective, perseguidor de pistas e interpretador de pautas discontinuas con las que completa un rompecabezas. Narrar la novela le confiere un rol esencial en la fabricación del texto ya que su observación y su participación directa en algunos de los episodios le confieren el saber necesario para completar el relato solucionando el crimen.

El proceso literario la escritura misma son tematizados en las tres novelas que estudiamos. Con tal finalidad, en Filosofía y L etras proliferan los textos y en L a tradución proliferan los códigos. Esta última novela dramatiza la imposibilidad de hallar o de construir una lengua universal, de sentido único. Transcribo aquí el epígrafe de Borges que precede al texto puesto que confirma, en una primera mise en abîme, la pluralidad de lecturas ofrecidas por un mismo texto:

Al recorrer con entusiasmo y credulidad la versión inglesa de cierto filósofo chino, di con este memorable pasaje: A un condenado a muerte no le importa bordear un precipicio, porque ha renunciado a la vida. En este punto el traductor colocó un asterisco y me advirtió que su interpretación era preferible a la de otro sinólogo rival que traducía de esta manera: L os sirvientes destruyen las obras de arte, para no tener que juzgar sus bellezas y sus defectos. Entonces, como Paolo y Francesca, dejé de leer. Un misterioso escepticismo se había deslizado en mi alma.

${ }^{6}$ Entre algunas de las reglas que Raymond Chandler señala para el género policial figura que la trama debe ser creíble desde el principio hasta el final y que tanto los personajes como los decorados y la atmósfera han de ser realistas. Patricia Highsmith aconseja a los escritores de novelas de suspenso hacer observaciones sobre la psicología de los personajes y mostrarse interesado por la justicia o su falta en el mundo así como por el coraje y la cobardía de los personajes. 
El escepticismo que reina en la novela se inscribe así en una larga genealogía literaria - Dante y Borges incluidos- que intenta recomponer fragmentos y crear versiones, siempre parciales y nunca definitivas. Retomo asimismo el párrafo que abre la novela describiendo un gesto del narrador que prefigura el relato. Se refiere a un faro de cerámica, recuerdo del viaje emprendido hacia el sur con motivo del congreso de traducción:

La superficie del faro está cubierta de estrías, porque ayer, al acomodar los originales de una traducción, el faro se cayó del escritorio. Con paciencia uní los pedazos: quien haya intentado rearmar un jarrón roto, sabe que, por minucioso que sea su empeño, hay fragmentos que nunca aparecen. (11)

El fragmento apela a una experiencia cotidiana gestual y también linguística: rearmar el pasado por la escritura es tarea difícil y el resultado nunca es satisfactorio porque el lenguaje -como los trozos de cerámica- es un medio fragmentario que impide la reconstrucción definitiva. La pluralidad de lenguajes y de interpretaciones está insistentemente recalcada en la novela: desde el caso de la mujer que traduce cada palabra que oye hasta el director del museo que transcribe el sonido del viento en Morse, desde la piel de los lobos marinos cuyas manchas forman signos hasta el idioma de los borrachos inteligible sólo para ellos, las anécdotas ilustran una gran pluralidad de sistemas comunicativos. La hipérbole resultante de la acumulación de sistemas comunicativos que pretenden encerrar un saber sagrado: la numerología, los lenguajes herméticos - tal el enoquiano- y los prebabélicos aseguran la ilusión del saber y de su transmisión con un efecto cómico-satírico. La búsqueda del valor absoluto y del significado único, propios del mítico lenguaje prebabélico concluye en el fracaso sumo, es decir en la muerte - tan ritual como las pesquisas- de los iniciados, en este caso, los cuatro estudiosos de la lengua enoquiana. La traducción dramatiza así el fracaso de la vanidad humana de conseguir un saber supremo. Todo 
lenguaje estará siempre sujeto a múltiples interpretaciones y significados contradictorios.

Es por eso que esta novela haga una crítica explícita a la novela policial clásica dando relieve a su propósito paródico. Uno de los traductores presentes en el congreso comenta que en una ocasión perdió el original de una novela policial que debía traducir: "Lo llamo al editor, me dice que no tiene otra copia, y que en dos días necesita la traducción. ¿Qué dibujo lleva la tapa? pregunto. Un enmascarado le clava un puñal a una pelirroja. La empuñadura tiene forma de lagartija. ¿Dice la contratapa donde ocurre la acción? En Nueva York. Pasé toda la noche traduciendo el original perdido. No estuvo mal la lagartija; tuvo tres ediciones" (33). La invención basada en algunos detalles es suficiente en este caso para crear un texto falsario pero eficaz. Pero lo más importante es que la cita comenta las novelas policiales norteamericanas de los años treinta, las llamadas "pulp fiction", cuyas portadas violentas resumían el terror provocado por la tortura y la amenaza sexual de sus páginas. Las novelas vueltas formulaicas por la repetición de episodios y de roles carecen de originalidad y cualquiera puede conseguir un relato que interprete la portada.

En el caso de las novelas de De Santis nada resulta formulaico; todo lo contrario, las narraciones se rebelan en contra de la tradición y de la autoridad, sobre todo, en contra de aquéllos que pretenden imponer su voluntad con una hermenéutica autoritaria. A los perturbadores cuestionamientos provocados por los abusos del poder político que dejaron marcas nefastas en el individuo y en el cuerpo social se añade el debate sobre la función de los intelectuales y de sus ciencias y metodologías. No hay duda que el reto a los intelectuales consiste en invitarlos a desafiar las teorías y críticas que convertidas en modas se aplican a ciegas. Los acercamientos a temas tan complejos y fundamentales no pueden cerrarse en conclusiones fáciles. Las novelas de De Santis incursionan en una polémica que busca formulaciones sin llegar aún a la solución. Criminal, narrador y lector quedan atrapados en una trama laberíntica en persecusión de respuestas. El final de la novela policial restablece 
usualmente un orden tranquilizador e incluso moralizante - celebra el triunfo del bien sobre el mal- pero las novelas bajo estudio provocan serios cuestionamientos que invitan a la reflexión y a la polémica.

\section{Bibliografía}

De Santis, Pablo. Filosofía y L etras. Buenos Aires: Planeta, 2002. . La traducción. Buenos Aires: Ediciones D estino, 2000. . El teatro de la memoria. Buenos Aires: Ediciones D estino, 2000.

Gamerro, Carlos. "Disparen sobre el policial negro". Ñ Revista de cultura. 13 de agosto de 2005.

Giardinelli, Mempo. El género negro. México: UAM, 1984.

Narcejac, Thomas. E sthétique du roman policier. París: Le Portulan, 1947.

Lesser, Robert. Pulp A rt. Nueva York: Sterling Publishing, 2005.

Todorov, Tzvetan. Poétique de la prose. París: Editions du Seuil, 1978. 